\title{
Rates and risk factors for drug resistance tuberculosis in Northeastern China
}

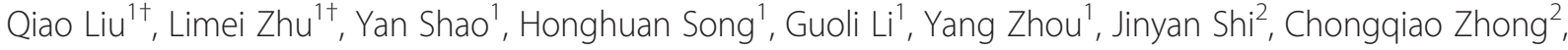 \\ Cheng Chen ${ }^{1 *}$ and Wei Lu ${ }^{1 *}$
}

\begin{abstract}
Background: Drug-resistant tuberculosis (TB) has emerged as a major challenge toward TB control and prevention. In Lianyungang city, the extent and trend of drug resistant TB is not well known. The objective of the survey was to assess drug resistance pattern of MTB and risk factors for drug resistant TB, including multidrug resistance tuberculosis (MDR-TB) in this area.

Methods: We performed drug susceptibility testing on Mycobacterium tuberculosis (MTB) isolates with first- and second-line anti-tuberculosis drugs of 1012 culture positive TB cases by using the proportion method, who were consecutively enrolled from January 2011 to December 2012 in Lianyungang city, China. The patterns of drug resistance in MTB were investigated and multiple logistic regression analysis was performed to assess the risk factors for drug resistant TB.

Results: Among the 1012 strains tested, 308 (30.4\%) strains were resistant to at least one first-line drug; the prevalence of MDR-TB was 88 (8.7\%), 5 (0.5\%) strains were found to be extensively drug-resistant tuberculosis (XDR-TB). Female gender was a risk factor for MDR-TB (adjusted odds ratio (aOR) $1.763,95 \% \mathrm{Cl}(1.060-2.934)$. The aged 28-54 years was significantly associated with the risk of MDR-TB with an aOR: 2.224, 95\% Cl (1.158-4.273) when compared with those 65 years or older. Patients with previous treatment history had a more than 7-fold increased risk of MDR-TB, compared with those never previously treated.
\end{abstract}

Conclusions: The burden of drug resistant TB cases is sizeable, which highlights an urgent need to reinforce control, detection and treatment strategies for drug resistant TB.

Keywords: Epidemiology, MDR-TB, Drug resistance, Drug susceptibility

\section{Background}

Tuberculosis (TB) remains a major global health problem, especially in high TB burden countries with large numbers of TB patients and poorer sanitation. TB ranks as the second leading cause of death among infectious diseases worldwide, following only the human immunodeficiency virus (HIV) [1]. According to the 2012 WHO global TB report, China ranks as 2nd among the world's 22 high burden countries with a TB incidence around 1 million, and the prevalence rate of TB was 104 per 100,000 patients (95\% confidence interval $[95 \% \mathrm{CI}] 91-119)$ and the

\footnotetext{
*Correspondence: chencheng128@gmail.com; jsjkmck@163.com ${ }^{\dagger}$ Equal contributors

'Department of Chronic Communicable Disease, Center for Disease Control and Prevention of Jiangsu Province, 172 Jiangsu Rd, Nanjing 210009, PR China

Full list of author information is available at the end of the article
}

incidence rate was 75 per 100,000 patients (95\% CI 6685) in 2011 [1].

In a nationwide survey in China in 2007, the estimated multidrug-resistant tuberculosis (MDR-TB) rate was $5.7 \%$ for new cases and $25.6 \%$ for previously treated cases. Approximately $8 \%$ of the patients with MDR-TB had extensively drug-resistant tuberculosis (XDR-TB) [2]. However, information on the prevalence of MDR and XDR-TB remains scant in the region. Drug-resistant Mycobacterium tuberculosis(MTB) strains, MDR-TB and XDR-TB strains may be the potential propellers for the spread of TB, and through now we put great efforts in TB control and treatment, the situation has not greatly improved. Despite poor compliance to chemotherapy duration, drug resistance of MTB would be another important factor for treatment failure among new TB cases

\section{Biomed Central}

(c) 2013 Liu et al.; licensee BioMed Central Ltd. This is an open access article distributed under the terms of the Creative Commons Attribution License (http://creativecommons.org/licenses/by/2.0), which permits unrestricted use, distribution, and reproduction in any medium, provided the original work is properly cited. 
[3], which may lead to a fall in successful TB cure rates [4].

Lianyungang city is located in the northeastern part of China, and covers an area of 7.5 thousand square kilometers with a population around 5 million in 2012. Information on the prevalence of MDR-TB and XDR-TB remains unknown in this region. Thus, we conducted this study to assess drug resistance patterns of MTB on first- and second-line anti-TB drugs in this region, and evaluated related risk factors of drug resistance among new and previously treated smear-positive TB patients.

\section{Methods}

\section{Study population and isolates}

In Lianyungang city, all newly registered patients with sputum smear-positive pulmonary tuberculosis were collected for strain identification and drug susceptibility testing (DST). From January 2011 to December 2012, a total of 1170 clinical isolates were collected from the sputum samples of pulmonary tuberculosis patients. In all surveys, each newly registered TB patient, positive on sputum smear microscopy, was interviewed by the clinician using the medical records to obtain the treatment history. The medical records include personal information, physical examinations, present illness, TB-related complaints, previous medical history, family history and PPD result. The treatment history of included cases was classified by medical staff into new and previously treated cases. New cases were defined as patients with tuberculosis who have never been treated with anti-TB drugs or received them for less than one month. Previously treated cases were defined as patients who have been treated for tuberculosis for at least one month. The definitions of new/previously treated cases referred to the WHO guidelines [5].

\section{Strain identification and drug susceptibility test}

The sputum samples were cultured and isolated on Lowenstein-Jensen (LJ) culture media which were prepared by the Baso biotechnology Ltd (Zhuhai, China). All the MTB isolates from positive culture were identified and subjected to DST. Identification of MTB was done using the p-Nitrobenzoic acid (PNB) method and the growth in LJ media containing PNB indicates that the bacilli do not belong to the MTB complex. Species other than MTB were excluded from the final analysis.

LJ media impregnated one anti-tuberculosis drug was used for DST, and the corresponding drug concentrations were as follows: $0.2 \mu \mathrm{g} / \mathrm{ml}$ for INH, $40 \mu \mathrm{g} / \mathrm{ml}$ for RMP, $4 \mu \mathrm{g} / \mathrm{ml}$ for SM, $2 \mu \mathrm{g} / \mathrm{ml}$ for EMB, $30 \mu \mathrm{g} / \mathrm{ml}$ for $\mathrm{KM}$ and $2 \mu \mathrm{g} / \mathrm{ml}$ for OFX. The LJ culture media were incubated at $37^{\circ} \mathrm{C}$. They were read twice at the first week to detect contaminations and/or fast growth of atypical mycobacteria and again every week thereafter for slower growing bacteria; if no bacteria grew by 6 weeks, the result was recorded as negative. Contaminated slant cultures were discarded, and additional decontamination and culture were undertaken using a stored portion of the original sample. Resistance was expressed as the percentage of colonies that grew on the drug-containing media compared to those on control media. The growth of colonies in the drug containing plate was compared to the control plate as a proportion. If the bacterial growth on the media with the specific drug was $\geq 1 \%$ compared to the control, the strain was declared resistant to the specific drug; or it was defined as sensitive when the growth rate was $<1 \%$ compared to the control. Strains isolation, identification and DST were performed at the fourth people's hospital of Lianyungang city. Procedures for external quality assurance for smear and culture were based on WHO guidelines [1]. For internal quality assurance of DST, a standard H37Rv strain was included with each new batch of LJ media. External quality control for culture and DST was conducted by the provincial TB reference laboratory, which participates in the annual proficiency review of DST organized by the Hong Kong Supranational Tuberculosis Reference Laboratory and has passed each review since 2010.

\section{MDR and XDR}

The following WHO-recommended definitions were used for resistant cases:

MDR-TB was defined as TB with resistance to at least INH and RMP. XDR-TB defined as MDR-TB plus resistance to a fluoroquinolone and at least one second-line injectable agent: amikacin, kanamycin and/or capreomycin [5]. In our study the XDR-TB was defined as TB with resistance to at least INH, RMP, KM and OFX.

\section{Statistical analysis}

For comparison of categorical variables, significance testing was done by $\mathrm{X}^{2}$ test with by 2 -sided Fisher exact test as appropriate. Associations between selected factors were estimated by computing odds ratios (ORs) and their 95\% confidence intervals (CIs) from an unconditional logistic regression model. The criterion for significance was set at $P<0.05$ based on a two-sided test. Analyses were conducted with SPSS version 13.0 (SPSS Inc., Chicago, IL, USA).

\section{Ethics statement}

Informed written consent was obtained from all patients and the study was approved by the Institutional Review Board of Jiangsu Provincial Center for Disease Control and Prevention. Ethics were respected throughout the study period. 


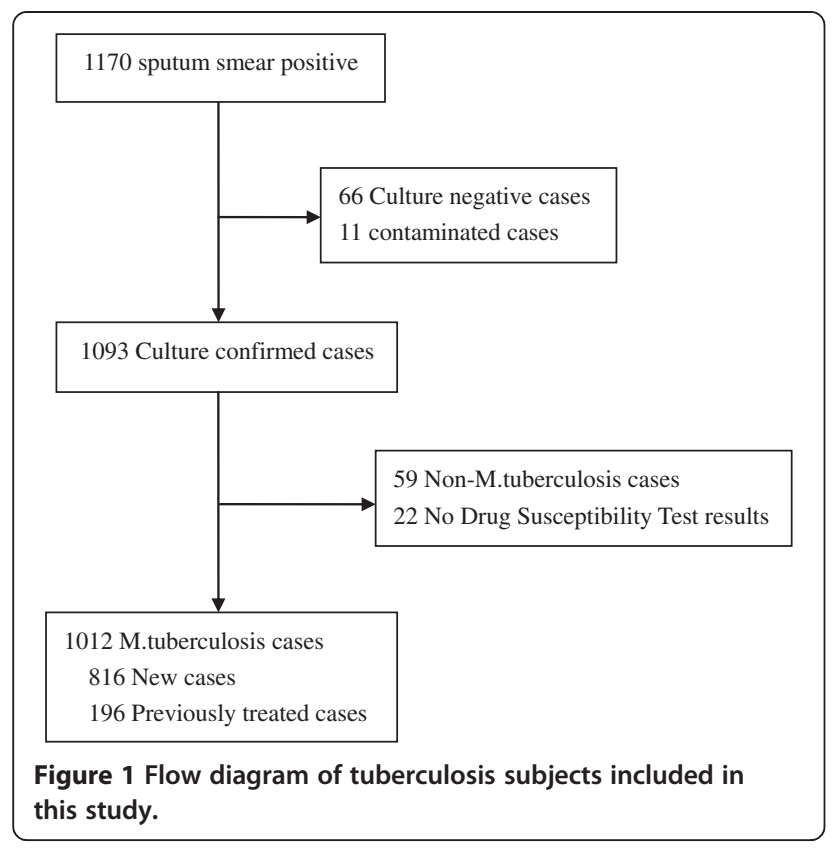

\section{Results}

\section{Bacterial strains and patient characteristics}

During the study period, 1170 sputum smear positive TB cases were enrolled and 1093 clinical isolates reported a culture positive MTB. Meanwhile, 66 cultured negative cases and 11 contaminated cases were excluded. Of the 1093 culture positive samples, 59 cultures were distinguished as Non-MTB (NTM). 22 samples failed for DST assay were excluded. Thus, 1012 samples were included in the final analysis (Figure 1). The age of the $1012 \mathrm{pa}-$ tients ranged from 14 to 90 years (mean \pm SD), $49.8 \pm$ 20.6, media 54), 748 (73.9\%) of them were male and 264 (26.1\%) were female. Of the 1012 case-patients included in the study, $816(80.6 \%)$ were new incidence and 196 $(19.4 \%)$ were previously treated. $9(0.9 \%)$ cases were migrants.859 (84.9\%) of the 1012 cases came from rural areas (Table 1).

\section{Prevalence of resistance to anti-tuberculosis drugs}

This study observed most resistance of isoniazid 184 (18.2\%) followed by streptomycin 141 (13.9\%), rifampicin 114 (11.3\%), ofloxacin 78 (7.7\%), ethambutol 72 (7.1\%), and kanamycin 42 (4.2\%). Among the new cases, drug resistance was reported in 191(23.4\%); INH resistance was reported in 91 (11.2\%), RMP resistance in 48 (5.9\%), EMB resistance in 30 (3.7\%), SM resistance in 90 (11.0\%), KM resistance in $28(3.4 \%)$, OFX resistance in $42(5.1 \%)$, Mono-resistance was found in 113 patients (13.8\%), MDR in $34(4.2 \%)$ and XDR in $0(0 \%)$. Among the 196 previously treated cases, drug resistance was reported in 117 (59.7\%); INH resistance was reported in 93 (47.4\%), RMP

Table 1 Characteristics of Patients with Culture Confirmed Pulmonary Tuberculosis: comparison of patients with any drug resistance, MDR-TB and XDR-TB

\begin{tabular}{|c|c|c|c|c|c|c|c|}
\hline Variable & Totally $1012, \mathrm{n}(\%)$ & Any drug resistance, $\mathrm{n}(\%)$ & $p$-Value & MDR-TB, n(\%) & $p$-Value & XDR-TB, n(\%) & $p$-Value \\
\hline \multicolumn{8}{|l|}{ Sex } \\
\hline Female & $264(26.1)$ & $89(33.7)$ & \multirow{2}{*}{0.178} & $32(12.1)$ & \multirow{2}{*}{0.022} & $3(1.1)$ & \multirow{2}{*}{$0.115^{*}$} \\
\hline Male & 748(73.9) & 219(29.3) & & $56(7.5)$ & & $2(0.3)$ & \\
\hline \multicolumn{8}{|l|}{ Age groups (years) } \\
\hline $0-28$ & $250(24.7)$ & $44(17.6)$ & \multirow{4}{*}{$<0.001$} & $13(5.2)$ & \multirow{4}{*}{0.002} & $1(0.4)$ & \multirow{4}{*}{$0.208^{*}$} \\
\hline $28-54$ & $254(25.1)$ & $94(37.0)$ & & $35(13.8)$ & & $1(0.4)$ & \\
\hline $54-65$ & $230(22.7)$ & $82(35.7)$ & & $23(10.0)$ & & $3(1.3)$ & \\
\hline $65+$ & $278(27.5)$ & $88(31.7)$ & & $17(6.1)$ & & $0(0)$ & \\
\hline \multicolumn{8}{|l|}{ Migrant population } \\
\hline Yes & $9(0.9)$ & $6(66.7)$ & \multirow{2}{*}{$0.027^{*}$} & $2(22.2)$ & \multirow{2}{*}{$0.181^{*}$} & $0(0)$ & \multirow{2}{*}{$1^{*}$} \\
\hline No & 1003(99.1) & $302(30.1)$ & & $86(8.6)$ & & $5(0.5)$ & \\
\hline \multicolumn{8}{|l|}{ Treatment history } \\
\hline New Cases & $816(80.6)$ & 191(23.4) & \multirow{2}{*}{$<0.001$} & $34(4.2)$ & \multirow{2}{*}{$<0.001$} & $0(0)$ & \multirow{2}{*}{$<0.001^{*}$} \\
\hline Pre Treated Cases & 196(19.4) & 117(59.7) & & $54(27.6)$ & & $5(2.6)$ & \\
\hline \multicolumn{8}{|l|}{ Region } \\
\hline Rural areas & 859(84.9) & $258(30.0)$ & \multirow{2}{*}{0.512} & $69(8.0)$ & \multirow{2}{*}{0.076} & $3(0.3)$ & \multirow{2}{*}{$0.167^{*}$} \\
\hline Urban Districts & 153(15.1) & $50(32.7)$ & & 19(12.4) & & $2(1.3)$ & \\
\hline \multicolumn{8}{|l|}{ Occupation } \\
\hline Farmer & 783(77.4) & $247(31.5)$ & \multirow{2}{*}{0.156} & $69(8.8)$ & \multirow{2}{*}{0.808} & $1(0.4)$ & \multirow{2}{*}{$1^{*}$} \\
\hline Non-farmer & $229(22.6)$ & $61(26.6)$ & & 19(8.3) & & $4(0.5)$ & \\
\hline
\end{tabular}

*Value by Fisher's exact test. 
resistance in 66 (33.7\%), EMB resistance in 42 (21.4\%), SM resistance in 51 (26.0\%), KM resistance in 14 (7.1\%), OFX resistance in 36 (18.4\%), Mono-resistance was present in 22 (11.2\%), MDR in 54 (27.6\%) and XDR in 5 (2.6\%) patients, respectively (Table 2 ).

\section{Factors associated with MDR-TB}

The univariate analysis revealed a higher proportion of female gender (cOR 1.704, 95\% CI 1.077-2.697), individuals aged 28-54 years (cOR 2.914, 95\% CI 1.502-5.652), and patients with previous TB treatment (cOR 8.746, 95\% CI 5.495-13.922) amongst MDR-TB patients. The final multivariable logistic regression model identified female gender (aOR 1.763, 95\% CI 1.060-2.934), aged 2854 years (aOR 2.224, 95\% CI 1.158-4.273) and previous history of TB treatment (aOR 8.910, 95\% CI 5.47814.492), to be associated with MDR-TB (Table 3).

\section{Discussion}

Information on anti-tuberculosis drug resistance levels is an essential management tool for evaluating the performance of national TB control programmers (NTPs). Resistance in previously treated cases is an indicator of current treatment practices in the community. Drug resistance in new cases reflects transmission of disease with resistant bacilli [6].

The prevalence of drug resistance in previously treated cases was higher than new cases for each drug alone as well as for all six drugs, as reported previously $[2,7,8]$. This suggests that retreatment is deficient and poses a threat to continued transmission, which has not yet manifested itself among new patients. The prevalence of MDR-TB was $4.2 \%$ in new cases and $27.6 \%$ in previously treated cases. As reported in a national survey of China, the rates for MDR-TB in new and previously treated cases were $5.7 \%$ and $25.6 \%$, respectively [2]. The MDRTB prevalence among previously treated cases was modestly higher than the national average, and among new cases the rate was slightly lower. MDR-TB was observed $2.8 \%-14.7 \%$ of new cases and $9.7 \%-34.3 \%$ of previously treated cases in China [2,9-12]. In Korea, resistance to at least one first-line drug was identified in $11.7 \%$ of new cases and $41.6 \%$ of previously treated cases. MDR-TB was detected in $3.9 \%$ of new cases and $27.2 \%$ of previously treated cases. The proportion of XDR-TB among MDR-TB patients was $16.7 \%$ (9/54) [13]. In Japan, The prevalence of MDR in new and previously treated cases was $0.7 \%$ and $9.8 \%$ respectively [14]. The overall MDRTB rate was $4.3 \% ; 2.5 \%$ in new cases and $13.9 \%$ in previously treated cases in Pakistan [15]. MDR-TB was $0.2 \%$ of new cases and $3.4 \%$ of previously treated cases in Madagascar [16]. In Cambodia, no single MDR-TB was found among the new cases and $3.1 \%$ in previously treated cases [17]. In Yemen, The prevalence of MDR in
Table 2 Prevalence of anti-tuberculosis drug resistance among $M$. tuberculosis isolates from new and previously treated patients the results of drug susceptibility pattern by type of case

\begin{tabular}{|c|c|c|c|}
\hline & $\begin{array}{c}\text { New cases } \\
\text { n (\%) }\end{array}$ & $\begin{array}{l}\text { Previously } \\
\text { treated n (\%) }\end{array}$ & $\begin{array}{c}\text { Combined } \\
\text { n (\%) }\end{array}$ \\
\hline Total strans tested & 816 & 196 & 1012 \\
\hline $\begin{array}{l}\text { Susceptibility to all } \\
\text { drugs }\end{array}$ & $625(76.6)$ & $79(40.3)$ & $704(69.6)$ \\
\hline $\begin{array}{l}\text { Susceptibility to } \\
\text { fist-line }\end{array}$ & $661(81.0)$ & $85(43.4)$ & 746(73.7) \\
\hline $\begin{array}{l}\text { Susceptibility to } \\
\text { second-line }\end{array}$ & $751(92.0)$ & 155(79.1) & $906(89.5)$ \\
\hline Any resistance & 191(23.4) & $117(59.7)$ & $308(30.4)$ \\
\hline $\mathrm{H}$ & $91(11.2)$ & $93(47.4)$ & 184(18.2) \\
\hline $\mathrm{R}$ & $48(5.9)$ & $66(33.7)$ & 114(11.3) \\
\hline E & $30(3.7)$ & $42(21.4)$ & $72(7.1)$ \\
\hline S & $90(11.0)$ & $51(26.0)$ & $141(13.9)$ \\
\hline K & $28(3.4)$ & $14(7.1)$ & $42(4.2)$ \\
\hline O & $42(5.1)$ & $36(18.4)$ & $78(7.7)$ \\
\hline Mono-resistance & 113(13.8) & $22(11.2)$ & 135(13.3) \\
\hline $\mathrm{H}$ only & $27(3.3)$ & $8(4.1)$ & $35(3.5)$ \\
\hline R only & $11(1.3)$ & $3(1.5)$ & $14(1.4)$ \\
\hline E only & $1(0.1)$ & 0 & $1(0.1)$ \\
\hline Sonly & $42(5.1)$ & $5(2.6)$ & $47(4.6)$ \\
\hline K only & $18(2.2)$ & $2(1.0)$ & $20(2.0)$ \\
\hline O only & $14(1.7)$ & $4(2.0)$ & $18(1.8)$ \\
\hline MDR-TB & $34(4.2)$ & $54(27.6)$ & $88(8.7)$ \\
\hline$H+R$ & $5(0.6)$ & $13(6.6)$ & $18(1.8)$ \\
\hline$H+R+E$ & $2(0.2)$ & $5(2.6)$ & $7(0.7)$ \\
\hline$H+R+S$ & $7(0.9)$ & $10(5.1)$ & $17(1.7)$ \\
\hline$H+R+K$ & 0 & 0 & 0 \\
\hline $\mathrm{H}+\mathrm{R}+\mathrm{O}$ & $2(0.2)$ & $5(2.6)$ & $7(0.7)$ \\
\hline$H+R+E+S$ & $7(0.9)$ & $4(2.0)$ & $11(1.1)$ \\
\hline$H+R+E+K$ & 0 & 0 & 0 \\
\hline $\mathrm{H}+\mathrm{R}+\mathrm{E}+\mathrm{O}$ & $4(0.5)$ & $4(2.0)$ & $8(0.8)$ \\
\hline$H+R+S+K$ & $1(0.1)$ & $1(0.5)$ & $2(0.2)$ \\
\hline $\mathrm{H}+\mathrm{R}+\mathrm{S}+\mathrm{O}$ & $2(0.2)$ & $1(0.5)$ & $3(0.3)$ \\
\hline $\mathrm{H}+\mathrm{R}+\mathrm{K}+\mathrm{O}$ & 0 & $1(0.5)$ & $1(0.1)$ \\
\hline$H+R+E+S+K$ & 0 & 0 & 0 \\
\hline $\mathrm{H}+\mathrm{R}+\mathrm{E}+\mathrm{S}+\mathrm{O}$ & $4(0.5)$ & $6(3.1)$ & $10(1.0)$ \\
\hline$H+R+E+K+O$ & 0 & $1(0.5)$ & $1(0.1)$ \\
\hline $\mathrm{H}+\mathrm{R}+\mathrm{S}+\mathrm{K}+\mathrm{O}$ & 0 & $1(0.5)$ & $1(0.1)$ \\
\hline $\mathrm{H}+\mathrm{R}+\mathrm{E}+\mathrm{S}+\mathrm{K}+\mathrm{O}$ & 0 & $2(1.0)$ & $2(0.2)$ \\
\hline XDR-TB & 0 & $5(2.6)$ & $5(0.5)$ \\
\hline
\end{tabular}

$\mathrm{H}$ : isoniazid, R: rifampicin, E: ethambutol, S: streptomycin, K: kanamycin and $\mathrm{O}$ : ofloxacin. MDR-TB defined as resistance to at least $H$ and R. XDR-TB defined as resistance to at least $\mathrm{H}, \mathrm{R}, \mathrm{K}$ and $\mathrm{O}$. 
Table 3 Factors associated with multi-drug resistant tuberculosis

\begin{tabular}{|c|c|c|c|c|c|c|c|c|}
\hline \multirow[t]{2}{*}{ Variable } & \multirow{2}{*}{$\begin{array}{c}\text { Non-MDR, } 924 \\
\text { n(\%) }\end{array}$} & \multirow{2}{*}{$\begin{array}{c}\text { MDR-TB, } 88 \\
\mathrm{n}(\%)\end{array}$} & \multicolumn{3}{|c|}{ Univariate } & \multicolumn{3}{|c|}{ Multivariate } \\
\hline & & & COR & $95 \% \mathrm{Cl}$ & $p$-Value & $\mathrm{aOR}$ & $95 \% \mathrm{Cl}$ & $p$-Value \\
\hline Female gender & $232(25.1)$ & $32(36.4)$ & 1.704 & $1.077-2.697$ & 0.022 & 1.763 & $1.060-2.934$ & 0.029 \\
\hline Age 28-54 yr & 219(23.7) & $35(39.8)$ & 2.914 & $1.502-5.652$ & 0.002 & 2.224 & $1.158-4.273$ & 0.016 \\
\hline migrant population & $7(0.8)$ & $2(2.3)$ & 3.047 & $0.623-14.894$ & $0.181^{*}$ & 4.385 & $0.807-23.821$ & 0.087 \\
\hline Previous TB treatment & $142(15.4)$ & $54(61.4)$ & 8.746 & $5.495-13.922$ & $<0.001$ & 8.910 & $5.478-14.492$ & $<0.001$ \\
\hline Rural areas & $790(85.5)$ & 69(78.4) & 0.616 & $0.359-1.057$ & 0.076 & 0.583 & $0.321-1.058$ & 0.076 \\
\hline
\end{tabular}

cOR, crude odds ratio; aOR, adjusted odds ratio, adjusted for sex, age, migrant population, treatment history and region. Values in boldface indicate a significant $(P<0.05)$ difference between Non-MDR and MDR-TB.

new and previously treated cases was 3\% and 9.4\% respectively [18].

Compared MDR-TB patients, patients with XDR-TB are more likely to die or have treatment failure $[19,20]$. The prevalence of XDR-TB among combined cases was $0.5 \%$; it was $0 \%$ and $2.6 \%$ (5 cases) in new and previously treated cases, respectively. XDR-TB was distributed widely, albeit sporadically. This might imply that China's treatment strategy has improved, but that community TB control is still insufficient [21]. The prevalence of XDR-TB in new cases was slightly lower than the national average $(0.5 \%)$. However, XDR-TB prevalence among previously treated cases was a little higher than the national average (2.1\%) [2]. These findings points to the need for interventions that will increase continuity of treatment and reduce the rate of treatment default, especially among patients treated within the hospital system [22].

As reported, $11 \%$ of new cases of tuberculosis and 16\% of previously treated cases were resistant to either INH or RMP (but not both) before they received standard first-line short-course treatment [2]. Resistance to these first-line drugs were usually not detected because culturing and drug susceptibility testing are not routinely performed at the local tuberculosis clinics. The use of standard first-line drugs in the treatment of these patients may increase the risk of relapse, treatment failure and acquired drug resistance [23-25].

Male or female TB patients could have different levels of risk for drug resistance due to differences in access to health-care services or exposure to other risk factors [5]. In the present study, the resistance rate to any drug was similar in female and male, but females were more likely to have MDR-TB than males, with an OR of 1.763 (95\% CI: 1.060-2.934), also reported in previous studies [8,26-29]. The reasons for the association between female gender and MDR-TB are not well known. We hypothesize that this association could be related to the fact that women spend a long period of time caring for men and others with MDR-TB both in households and in healthcare settings in China where the majority of health care workers are female $[26,27]$. TB diagnosis and DST may be delayed among female patients, making treatment more difficult and inappropriate chemotherapeutic regimens more likely [30,31]. It is also possible that referring patients to the hospital may be different for male and female patients and the providers may feel reluctant to refer female patients with less complicated infection to a tertiary care center [32]. Discovering gender disparities associated with the risks of MDR-TB could provide insight into the development of targeted measures and improve access to health care and reduce the risk of acquiring drug-resistance.

We also found that age was a significant factor in the development of drug resistance. Resistance to any drug and MDR was highest in those aged 28-54 years. The association between age and the risk of MDR-TB is not well established in the literature as different studies use different cut-off points for age groups. However, it was also reported that MDR-TB patients were more likely to be younger than 65 years $[33,34]$. We assumed that agerelated difference in treatment adherence might be a possible explanation, as patients at 28-54 years old were often occupied by study, work or other activities on a daily basis, in contrast with the more sedentary lifestyle of elderly patients [34].

Many other risk factors for drug resistance tuberculosis and MDR-TB have been identified in recent studies: such as irregular treatment [35], urban residence [12], non-permanent residents [34], urban migration [12], lack of a sewage system in the home [35], frequent travelers [34], alcoholism plus smoking, and lung cavities [35]. Other important risk factors are associated with the supply or quality of the drugs, the possible inadequate drug intake by patients, and others, such as the lack of full supervision during the intensive phase of treatment [36], poor NTPs [14,17], and the possible high prevalence of highly virulent MDR-TB strains of MTB $[17,18,37]$.

There are several limitations of this survey. First, these is potential misclassification of the new and previously treated cases when some cases registered as new but may actually have had TB treatment in the past. Second, the burden of XDR-TB was underestimated because only resistance to ofloxacin and kanamycin not resistance to 
capreomycin or other aminoglycosides. Third, classification was based on patient history of prior treatment for $\mathrm{TB}$ and reviewing of medical records (which were not available for all patients enrolled). Fourth, this survey did not collect information on HIV infection status because patients with tuberculosis in China are not routinely tested for HIV.

\section{Conclusions}

This is the first prevalence survey on resistance to the six major anti-tuberculosis drugs in Lianyungang city. Our study showed that the high prevalence of drug resistance is a major challenge for TB control. Patients with previous treatment history and female gender are risk factors for MDR-TB. Prevention and control of drug-resistant TB should be emphasized by the revised DOTS program through prompt case detection as well as routine and quality-assured DST.

\section{Competing interests}

The authors declare that they have no competing interests.

\section{Authors' contributions}

QL, LZ, WL conceived the study, analyzed the data and drafted the manuscript; YS, HS, GL, JS participated in the study design, implemented the field investigation and performed DST tests; YZ, CZ and CC participated in the study design and helped draft the manuscript. All authors contributed to the study and have read and approved the final manuscript.

\section{Acknowledgements}

This study was supported by the National Nature Science Foundation of China (81302480), Key personnel of Science and Education Industrial Engineering (JKRC2011005), Provincial Department of Public Health of Jiangsu (Y201030), Key Medical Disciplines of Jiangsu Province (XK201150) and Ministry of Health (W201208). The sponsors have no role in the study design or data analysis.

We also thank Christopher Whalen, M.D., M.S. and Leonardo Martinez, MPH of Department of Epidemiology and Biostatistics, Miller Hall College of Public Health University of Georgia for their careful reviewing of this manuscript.

\section{Author details}

${ }^{1}$ Department of Chronic Communicable Disease, Center for Disease Control and Prevention of Jiangsu Province, 172 Jiangsu Rd, Nanjing 210009, PR China. ${ }^{2}$ Department of Chronic Communicable Disease, Center for Disease Control and Prevention of Lianyungang City, Lianyungang, PR China.

Received: 6 June 2013 Accepted: 9 December 2013

Published: 13 December 2013

\section{References}

1. WHO: World Health Organization: Global tuberculosis control. WHO report 2012. http://wwwwhoint/tb/publications/global_report/gtbr12_mainpdf 2012, website WHO report.

2. Zhao Y, Xu S, Wang L, Chin DP, Wang S, Jiang G, Xia H, Zhou Y, Li Q, Ou X National survey of drug-resistant tuberculosis in China. N Engl J Med 2012, 366(23):2161-2170

3. Iwamoto T, Yoshida S, Suzuki K, Tomita M, Fujiyama R, Tanaka N, Kawakami $Y$, Ito M: Hypervariable loci that enhance the discriminatory ability of newly proposed 15-loci and 24-loci variable-number tandem repeat typing method on Mycobacterium tuberculosis strains predominated by the Beijing family. FEMS Microbiol Lett 2007, 270(1):67-74

4. Glynn J, Vyonycky E, Fine P: Influence of sampling on estimates of clustering and recent transmission of Mycobacterium tuberculosis derived from DNA fingerprinting techniques. Am J Epidemiol 1999, 149(4):366-371.
5. Organization WH: Multidrug and extensively drug-resistant TB (M/XDR-TB): 2010 global report on surveillance and response. Geneva: World Health Organization; 2010

6. Chonde T, Basra D, Mfinanga S, Range N, Lwilla F, Shirima R, Van Deun A, Zignol M, Cobelens F, Egwaga S: National anti-tuberculosis drug resistance study in Tanzania. Int J Tuberc Lung Dis 2010, 14(8):967-972.

7. Yu C-C, Chang C-Y, Liu C-E, Shih L-F, Hsiao J-H, Chen C-H: Drug resistance pattern of $<\mathrm{i}>$ mycobacterium tuberculosis $</ \mathrm{i}>$ complex at a Medical Center in Central Taiwan, 2003-2007. J Microbiol Immunol Infect 2010, 43(4):285-290.

8. Shao Y, Yang D, Xu W, Lu W, Song H, Dai Y, Shen H, Wang J: Epidemiology of anti-tuberculosis drug resistance in a chinese population: current situation and challenges ahead. BMC Public Health 2011, 11:110.

9. Liu Q, Yang D, Xu W, Wang J, Lv B, Shao Y, Song H, Li G, Dong H, Wan K, et al: Molecular typing of mycobacterium tuberculosis isolates circulating in Jiangsu Province, China. BMC Infect Dis 2011, 11:288.

10. Li $X$, Wang $H$, Jing $H$, Wang $Y, Y u$ C, Wang J, Liu Z, Graviss E, Ma X: Population-based surveillance of extensively drug-resistant tuberculosis in Shandong Province, China [Short communication]. Int J Tuberc Lung Dis 2012, 16(5):612-614

11. Hu Y, Mathema B, Wang W, Hoffner S, Kreiswirth B, Xu B: Prevalence of multidrug-resistant pulmonary tuberculosis in counties with different duration of DOTS implementation in rural China. Microb Drug Resist 2008, 14(3):227-232.

12. Shen X, DeRiemer K, Yuan Z-A, Shen M, Xia Z, Gui X, Wang L, Gao Q, Mei J: Drug-resistant tuberculosis in Shanghai, China, 2000-2006: prevalence, trends and risk factors. Int J Tuberc Lung Dis 2009, 13(2):253-259.

13. Choi JC, Lim SY, Suh GY, Chung MP, Kim H, Kwon OJ, Lee NY, Park YK, Bai $\mathrm{GH}, \mathrm{Koh}$ W-J: Drug resistance rates of Mycobacterium tuberculosis at a private referral center in Korea. J Korean Med Sci 2007, 22(4):677-681.

14. Chacón L, Laínez M, Rosales E, Mercado M, Caminero J: Evolution in the resistance of Mycobacterium tuberculosis to anti-tuberculosis drugs in Nicaragua. Int J Tuberc Lung Dis 2009, 13(1):62-67.

15. Yoshikawa T: Tuberculosis in aging adults. J Am Geriatr Soc 1992, 40(2):178.

16. Wright A, Zignol M, Van Deun A, Falzon D, Gerdes SR, Feldman K, Hoffner S, Drobniewski F, Barrera L, van Soolingen D: Epidemiology of antituberculosis drug resistance 2002-07: an updated analysis of the Global Project on Anti-Tuberculosis Drug Resistance Surveillance. Lancet 2009, 373(9678):1861-1873.

17. Caminero J: Likelihood of generating MDR-TB and XDR-TB under adequate National Tuberculosis Control Programme implementation [Review article]. Int J Tuberc Lung Dis 2008, 12(8):869-877.

18. Dye C: Doomsday postponed? Preventing and reversing epidemics of drug-resistant tuberculosis. Nat Rev Microbio/ 2009, 7(1):81-87.

19. Kim H-R, Hwang SS, Kim HJ, Lee SM, Yoo C-G, Kim YW, Han SK, Shim Y-S, Yim J-J: Impact of extensive drug resistance on treatment outcomes in non-HIV-infected patients with multidrug-resistant tuberculosis. Clin Infect Dis 2007, 45(10):1290-1295.

20. Banerjee R, Allen J, Westenhouse J, Oh P, Elms W, Desmond E, Nitta A Royce S, Flood J: Extensively drug-resistant tuberculosis in California, 1993-2006. Clin Infect Dis 2008, 47(4):450-457.

21. Jou R, Chiang CY, Huang WL: Distribution of the Beijing family genotypes of Mycobacterium tuberculosis in Taiwan. J Clin Microbiol 2005, 43(1):95-100.

22. Organization WH: Engaging all health care providers in TB control: guidance on implementing public-private mix approaches. Geneva: World Health Organization; 2006

23. Yoshiyama $\mathrm{T}$, Yanai $\mathrm{H}$, Rhiengtong $\mathrm{D}$, Palittapongarnpim $\mathrm{P}$, Nampaisan $\mathrm{O}$ Supawitkul S, Uthaivorawit W, Mori T: Development of acquired drug resistance in recurrent tuberculosis patients with various previous treatment outcomes. Int J Tuberc Lung Dis 2004, 8(1):31-38.

24. Lew W, Pai M, Oxlade O: Initial drug resistance and tuberculosis treatment outcomes. Ann Intern Med 2008, 149:123-134.

25. Mak A, Thomas A, del Granado M, Zaleskis R, Mouzafarova N, Menzies D: Influence of multidrug resistance on tuberculosis treatment outcomes with standardized regimens. Am J Respir Crit Care Med 2008, 178(3):306-312.

26. Vashakidze L, Salakaia A, Shubladze N, Cynamon M, Barbakadze K, Kikvidze M, Papitashvili L, Nonikashvili M, Solomonia N, Bejanishvili N: Prevalence and risk factors for drug resistance among hospitalized TB patients in Georgia. Int J Tuberc Lung Dis 2009, 13(9):1148 
27. Mdivani N, Zangaladze E, Volkova N, Kourbatova E, Jibuti T, Shubladze N, Kutateladze T, Khechinashvili G, del Rio C, Salakaia A: High prevalence of multidrug-resistant tuberculosis in Georgia. Int J Infect Dis 2008, 12(6):635

28. Toungoussova O, Caugant D, Sandven P, Mariandyshev A, Bjune G: Drug resistance of Mycobacterium tuberculosis strains isolated from patients with pulmonary tuberculosis in Archangels, Russia. Int I Tuberc Lung Dis 2002, 6(5):406-414.

29. Lockman S, Kruuner A, Binkin NJ, Levina K, Wang YC, Danilovitsh M, Hoffner SE, Tappero JW: Clinical outcomes of Estonian patients with primary multidrug-resistant versus drug-susceptible tuberculosis. Clin Infect Dis 2001, 32(3):373-380.

30. Chiang C, Chang C, Chang R, Li C, Huang R: Patient and health system delays in the diagnosis and treatment of tuberculosis in Southern Taiwan. Int J Tuberc Lung Dis 2005, 9(9):1006-1012.

31. Long NH, Johansson E, Lonnroth K, Eriksson B, Winkvist A, Diwan V: Longer delays in tuberculosis diagnosis among women in Vietnam. Int I Tuberc Lung Dis 1999, 3(5):388-393.

32. Jeon CY, Hwang SH, Min JH, Prevots DR, Goldfeder LC, Lee H, Eum SY, Jeon DS, Kang HS, Kim JH: Extensively drug-resistant tuberculosis in South Korea: risk factors and treatment outcomes among patients at a tertiary referral hospital. Clin Infect Dis 2008, 46(1):42-49.

33. Faustini $A$, Hall AJ, Perucci CA: Risk factors for multidrug resistant tuberculosis in Europe: a systematic review. Thorax 2006, 61(2):158-163.

34. Law W, Yew W, Chiu Leung C, Kam K, Tam C, Chan C, Leung C: Risk factors for multidrug-resistant tuberculosis in Hong Kong. Int I Tuberc Lung Dis 2008, 12(9):1065-1070.

35. Barroso EC, Mota RMS, Santos RO, Sousa ALO, Barroso JB, Rodrigues JLN: Risk factors for acquired multidrug-resistant tuberculosis. J Pneumol 2003, 29(2):89-97.

36. Gandhi NR, Moll A, Sturm AW, Pawinski R, Govender T, Lalloo U, Zeller K, Andrews J, Friedland G: Extensively drug-resistant tuberculosis as a cause of death in patients co-infected with tuberculosis and HIV in a rural area of South Africa. Lancet 2006, 368(9547):1575-1580.

37. Amor YB, Nemser B, Singh A, Sankin A, Schluger N: Underreported threat of multidrug-resistant tuberculosis in Africa. Emerg Infect Dis 2008, 14(9):1345.

doi:10.1186/1471-2458-13-1171

Cite this article as: Liu et al:: Rates and risk factors for drug resistance tuberculosis in Northeastern China. BMC Public Health 2013 13:1171.

\section{Submit your next manuscript to BioMed Central and take full advantage of:}

- Convenient online submission

- Thorough peer review

- No space constraints or color figure charges

- Immediate publication on acceptance

- Inclusion in PubMed, CAS, Scopus and Google Scholar

- Research which is freely available for redistribution

Submit your manuscript at www.biomedcentral.com/submit
() Biomed Central 